(c) American Dairy Science Association, 2007.

\title{
Solvent Type Affects the Number, Distribution, and Relative Quantities of Volatile Compounds Found in Sweet Whey Powder
}

\author{
R. A. Prososki, M. R. Etzel, and S. A. Rankin ${ }^{1}$ \\ Department of Food Science, University of Wisconsin, Madison 53706
}

\section{ABSTRACT}

This study compares the performance of diethyl ether, methylene chloride, methyl formate, and pentane in the analysis of volatile flavor components in sweet whey powder. Extracts were prepared from sweet whey powder using each solvent. Volatile components were isolated by solvent extraction followed by solvent-assisted flavor evaporation. Gas chromatography-mass spectroscopy, coelution with known standards, and retention indices were used to identify the volatile compounds. Sixty total compounds were either positively or tentatively identified across all 4 solvents, but the number, distribution between the molecular classes, and relative quantities detected depended on solvent type. The highest number, widest distribution, and greatest relative quantities were found using methylene chloride and methyl formate, whereas diethyl ether and especially pentane were noticeably less effective. Results are characterized using molecular-based characteristics of solvents and solutes including dipole moment, dielectric constant, Log P (octanol-water partition coefficient), polarizability, water solubility, and Lewis acidity/basicity. Polarity and acidity/basicity were the primary factors that determined solvent performance. This work establishes a molecular-level basis for the selection of solvents in the analysis of sweet whey powder flavors.

Key words: solvent, volatile, sweet whey powder

\section{INTRODUCTION}

The determination of flavor-active compounds in foods is an established area of research. Several different techniques exist to extract volatile compounds from a food matrix including extraction with organic solvents. Solvent choice is a critical factor in determining volatile compound recovery and efficiency of an extraction method. Three solvents that have been widely used in many food extractions include pentane (PN), methyl-

Received August 7, 2006.

Accepted September 18, 2006

${ }^{1}$ Corresponding author: sarankin@wisc.edu ene chloride (MC), and diethyl ether (DE). Diethyl ether has been one of the most frequently used solvents for extraction of volatile compounds over the last decade, but few studies provide a justification for its use. One solvent not typically used in volatile extractions is methyl formate (MF). The 4 solvents differ in extraction efficiencies due to differences in chemical and physical properties (Table 1). Diethyl ether is less effective at extracting polar compounds in a variety of foods primarily due to its highly nonpolar character. Methyl formate and MC would predictably extract more polar compounds due to their greater polar character, as expressed by their larger dipole moments and dielectric constants and lower Log $\mathrm{P}$ values. Because $\mathrm{PN}$ is relatively insoluble in water and very nonpolar, it would predictably extract greater numbers and relative quantities of increasingly nonpolar compounds. The compatibility between the molecular and physical properties of the solvent and volatile solute is critical in selecting an appropriate solvent.

Other factors affecting solvent selection include flammability, toxicity, cost, reactivity, and stability. Understanding the potential hazards (e.g., flammability, toxicity, and stability) during storage is critical because it requires more caution in its use and handling. Using the National Fire Protection Association (NFPA) rating system for flammable and combustible liquids, $\mathrm{MC}$ has the lowest flammability rating $(\mathrm{NFPA}=1)$ whereas DE (NFPA = 4), PN (NFPA = 4), and MF $(\mathrm{NFPA}=4)$ have the highest flammability rating, because of their high volatility and low ignition temperatures. Solvent toxicity is another determinant in solvent selection for extractions, especially in the case where sensory detection is utilized; for example, GC-olfactometry. Diethyl ether has an oral $\left(\mathrm{LD}_{50(\mathrm{rat})}=1,215,000 \mu \mathrm{g} /\right.$ $\mathrm{kg})$ and inhalation $\left(\mathrm{LD}_{50(\mathrm{rat})}=73,000,000 \mu \mathrm{g} / \mathrm{kg} ; 2 \mathrm{~h}\right)$ toxicity that is relatively similar to the oral $\left(\mathrm{LD}_{50(\mathrm{rat})}=\right.$ $1,600,000 \mu \mathrm{g} / \mathrm{kg})$ and inhalation $\left(\mathrm{LD}_{50 \text { (rat) }}=88,000 \mu \mathrm{g} /\right.$ $\mathrm{kg} ; 30 \mathrm{~min}$ ) toxicities of MC (National Research Council, 1995). However, inhalation of high concentrations of DE can cause sedation, unconsciousness, and respiratory paralysis; high concentrations of $\mathrm{MC}$ vapor $(>500,000$ $\mu \mathrm{g} / \mathrm{kg}$ for $8 \mathrm{~h}$ ) can cause less detrimental effects such as lightheadedness, fatigue, and nausea (National Re- 
PROSOSKI ET AL.

Table 1. Chemical and physical properties of commonly used solvents amenable to volatile compound extractions

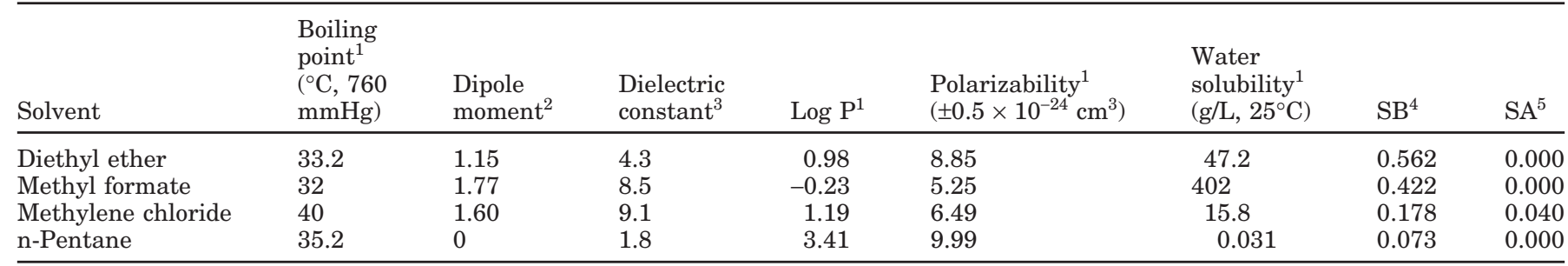

${ }^{1}$ Values obtained from Advanced Chemistry Development, Inc., 2006; Log P = log of octanol/water partition.

${ }^{2}$ Values obtained from Univ. Southern Maine (http://www.usm.maine.edu/ newton/Chy251_253/Lectures/Solvents/Solvents.html) and Buyong et al., 2000.

${ }^{3}$ Values obtained from ASI Instruments Inc., 2006.

${ }^{4} \mathrm{SB}=$ Solvent basicity; values obtained from Catalan et al., 1996.

${ }^{5} \mathrm{SA}=$ Solvent acidity; values obtained from Catalan and Diaz, 1997.

search Council, 1995). Methyl formate has an oral $\left(\mathrm{LD}_{50 \text { (rat) }}=1,500,000 \mu \mathrm{g} / \mathrm{kg}\right)$ toxicity similar to $\mathrm{MC}$, and a lower inhalation toxicity $\left(\mathrm{LD}_{50 \text { (rat) }}=50,000,000 \mu \mathrm{g} /\right.$ $\mathrm{kg} ; 30 \mathrm{~min}$; Chemical Land 21, 2000). Pentane is moderately toxic (oral $\mathrm{LD}_{50 \text { (rat) }}>2,000,000 \mu \mathrm{g} / \mathrm{kg}$; inhalation $\mathrm{LC}_{50 \text { (rat) }}=364 \mu \mathrm{g} / \mathrm{kg}$; Chemical Land 21, 2000). Inhalation of PN may result in nausea, dizziness, or irritation of the mucous membrane of the nose and throat.

The only solvent that exhibits high hazards during storage is DE. Over time, it has a potential explosive hazard due to the formation of unstable peroxides promoted by exposure to oxygen, light, and strong oxidizing agents. Pentane, MC, and MF exhibit fewer hazards than DE during storage under normal conditions (National Research Council, 1995).

The level and spectrum of volatile compounds obtained after extraction and GC-MS analysis is expected to be highly dependent on the solvent selection. To date, few recent studies have considered the effects of solvent properties on the extraction of volatile compounds from foods. This study will compare the types and relative quantities of volatile compounds extracted from sweet whey powder (SWP) by DE, PN, MF, and MC as related to the molecular and physical properties of the solvents and solutes.

\section{MATERIALS AND METHODS}

\section{SWP Composition}

Commercial SWP (Cheddar cheese whey, US extra grade, Foremost Farms Inc., Baraboo, WI) aged for 4 yr under ambient conditions was selected for analysis. The $\mathrm{pH}$ was measured using a $\mathrm{pH}$ electrode (Accumet AB15, Fisher Scientific, Pittsburgh, PA) on a 6.5-g SWP sample in $100 \mathrm{~mL}$ of distilled water (Sithole et al., 2005). Free moisture content was determined by a standard oven-drying method (Marth, 1985). Fat content was determined by the Mojonnier method (method 989.05;
AOAC, 2000). Ash content was determined using a muffle furnace at $535^{\circ} \mathrm{C}(\operatorname{method} 935.42 ; \mathrm{AOAC}, 2000)$. The lactose content was determined using an enzymatic method (984.15; AOAC, 1995). Volhard's method (method 935.43; AOAC, 2000) was used to determine the salt content. The protein content was determined by the Kjeldahl method (methods 930.29, 991.20; AOAC, 2000). Sample color was determined by colorimeter (Colorquest 45/0, Hunterlab, Reston, VA). All analyses were done in triplicate. The average chemical characteristics ( \pm standard deviation) of the SWP samples were as follows: moisture $=4.72 \% \pm 0.12$; protein $=$ $13.2 \% \pm 0.03$; fat $=1.04 \% \pm 0.10$; lactose $=63.9 \% \pm 0.4$; ash $=5.39 \% \pm 0.05 ;$ salt $=0.34 \% \pm 0.05 ;$ and $\mathrm{pH}=5.58$ \pm 0.01 . Colorimeter results were $L^{*}=77 \pm 0.15$, $a^{*}=$ $4.3 \pm 0.068$, and $b^{*}=28 \pm 0.12$. Results were consistent with those reported by Banavara et al. (2003); thus, the SWP selected would be considered to be in legal compliance with respect to US compositional standards. The colorimeter values are reflective of whey that has undergone some browning, resulting in a possible reduction in lactose and protein levels.

\section{Preparation of Extracts}

Sweet whey powder $(8.0 \mathrm{~g})$ was extracted with $25 \mathrm{~mL}$ of each solvent in a tightly capped $40-\mathrm{mL}$ vial for $1 \mathrm{~h}$ with mild, intermittent, manual shaking every $15 \mathrm{~min}$. The 4 solvents used were DE (Sigma-Aldrich, Inc., St. Louis, MO), MC (Sigma-Aldrich, Inc.), MF (Acros Organics, Morris Plains, NJ), and PN (Acros Organics). At $1 \mathrm{~h}$, the samples were centrifuged at $1,200 \times g$ for 2 min. The supernatant was pipetted from the vial and collected in a $100-\mathrm{mL}$ glass vial with a Teflon-lined lid. The SWP was resuspended in an additional $25 \mathrm{~mL}$ of solvent and the extraction was repeated as above for a total of $3 \times 25 \mathrm{~mL}$ of each solvent per SWP sample. The combined extracts $(\sim 75 \mathrm{~mL})$ were distilled under 
vacuum $(709 \mathrm{~mm} \mathrm{Hg})$ at $50^{\circ} \mathrm{C}$ by solvent-assisted flavor evaporation to separate volatile compounds from nonvolatile compounds (Engel et al., 1999). After distillation, external standards (1.8 ppm of 2-methyl-3-heptanone and $1.6 \mathrm{ppm}$ of 2-methylpentanoic acid in $5 \mathrm{~mL}$ of methanol) were added to each extract to correct for injection errors. Samples were dried using approximately $1 \mathrm{~g}$ of anhydrous sodium sulfate (Fisher Scientific, Fair Lawn, NJ) before concentration to $0.5 \mathrm{~mL}$ under a stream of nitrogen. Duplicate extractions of an additional 2 separate SWP samples were completed with each solvent.

\section{GC-MS}

Volatile compound analysis was performed using a gas chromatograph (Agilent 6890N, Agilent Technologies, Inc., Palo Alto, CA) with a mass selective detector (Agilent 5973 MS, Agilent Technologies, Inc.). Data analysis was performed using the accompanying computer software (ChemStation Software Rev. D.02.00 SP1, Agilent Technologies, Inc.). Chromatographic separation of the volatile compounds was achieved using a fused silica capillary column (RTX-Wax, $30 \mathrm{~m}$ long $\times$ $0.25 \mathrm{~mm}$ i.d. $\times 0.5 \mu \mathrm{m}$ film thickness; Restek Corp., Bellefonte, PA). Helium was the carrier gas at a constant flow rate of $0.8 \mathrm{~mL} / \mathrm{min}$. The oven temperature was programmed from 40 to $220^{\circ} \mathrm{C}$ at a rate of $10^{\circ} \mathrm{C} /$ min with initial and final holding times of 5 and 10 min, respectively. Electron impact ionization was used with a voltage of $70 \mathrm{eV}$. An $\mathrm{m} / z$ scan range of 29 to 350 amu was collected at $4.44 \mathrm{scans} / \mathrm{s}$. Samples $(1 \mu \mathrm{L})$ were injected in the splitless mode.

\section{Identification of Volatile Compounds}

Positive identification of odorants was made by 3 determinants: 1) mass spectra (NIST version 1.7 mass spectral database; Agilent Technologies, Inc.), 2) coelution with a known standard by injecting a series of alkanes $\left(\mathrm{C}_{6}\right.$ to $\left.\mathrm{C}_{28}\right)$ into the $\mathrm{GC}$ using the conditions above, and 3) comparison of a calculated retention indices (RI) to a referenced Kovats index (KI; Kovats, 1958; Karagul-Yuceer et al., 2001, 2002; Acree and Arn, 2004; Mahajan et al., 2004; El-Sayed, 2005). Compound identity was considered tentative if only 1 or 2 of the 3 criteria matched. The degree of identification is reported in Table 2 .

\section{RESULTS}

Sixty compounds were identified ( 29 positive and 31 tentative across all 4 solvents) and assigned into 1 of 10 classes of compounds based on their major common moieties as follows: alcohols, ketones, carboxylic acids, aldehydes, amines, amides, esters, sulfur-containing compounds, aromatic compounds, and furanic compounds (Table 2). Solvent performance was compared based on the number, distribution, and relative quantities of compounds detected within each class. The highest number of compounds was detected using MC (42), followed by MF (37), DE (35), and PN (25).

The distribution of compounds was defined as the number of different compounds detected in each solvent extract within each class of compounds. A solvent was considered to exhibit distribution effectiveness if greater than $50 \%$ of the total compounds per class were detected at any concentration. For example, 5 of 6 ketones were detected using MC, 4 of 6 using MF, 3 of 6 using DE, and 2 of 6 using PN. Therefore, the solvents $\mathrm{MC}$ and MF were deemed effective for extraction of ketones, whereas DE and PN were not. Using this criterion, effective extraction distributions of the following flavor compound classes for each solvent are as follows: MC-ketones, carboxylic acids, aldehydes, amines, amides, sulfur-containing compounds and furanic compounds; MF-ketones, carboxylic acids, aldehydes, sulfur-containing compounds, and furanic compounds; DE-carboxylic acids, aldehydes, amides, and furanic compounds; and $\mathrm{PN}-$ esters and aromatic compounds. The widest distributions for all classes of compounds were found using $\mathrm{MC}$ and $\mathrm{MF}$, whereas the distributions using $\mathrm{DE}$ and $\mathrm{PN}$ were the narrowest.

The relative percentage quantities extracted by the respective solvents were compared as follows. Each flavor compound quantity was expressed as a percentage of the average maximum standardized peak area for a given compound in each class (Figure 1 and Table 2). For example, for ketones, MC had the highest relative quantity of pantolactone of the 4 solvents $(\mathrm{MC}=$ $0.10, \mathrm{MF}=0.076, \mathrm{DE}=0.025, \mathrm{PN}=0.016)$ and was used as the divisor for all 4 relative quantities to determine the percentage of peak area $(\mathrm{MC}=100 \%, \mathrm{MF}=$ $76 \%, \mathrm{DE}=25 \%, \mathrm{PN}=16 \%)$. Using these latter percentages, if the percentage relative quantity of a given compound exceeded $50 \%$, it was included in the total number of compounds recovered at high quantities for a particular class of compounds. For example, pantolactone was included as 1 of the 6 total ketones with relatively high quantities for $\mathrm{MC}$ and $\mathrm{MF}$, but not for $\mathrm{DE}$ and PN. Finally, a solvent was considered effective in the extraction of relative quantities for a particular class of flavor compounds when greater than $50 \%$ of the total compounds in each class exceeded the $50 \%$ relative peak area. Using this criterion, effective detection of the following flavor compounds was found for each solvent: MC-ketones, carboxylic acids, amines, amides, and sulfur-containing compounds; $\mathrm{MF}$ - car- 
Table 2. Alcohols, ketones, acids, aldehydes, amines, amides, esters, sulfur-containing compounds, aromatic compounds, and furanic compounds found in SWP using direct solvent extraction with diethyl ether, methyl formate, methylene chloride and pentane analyzed by GC-MS on a capillary polyethyleneglycol column (values in parentheses are standard deviations)

\begin{tabular}{|c|c|c|c|c|c|c|c|c|c|}
\hline \multirow[b]{2}{*}{ Compound } & \multirow[b]{2}{*}{$\mathrm{RI}^{1}$} & \multirow[b]{2}{*}{$\mathrm{ID}^{2}$} & \multicolumn{4}{|c|}{ Standardized relative peak area ${ }^{3}$} & \multirow[b]{2}{*}{$\log \mathrm{P}^{4}$} & \multirow{2}{*}{$\begin{array}{l}\mathrm{BP}^{4}\left({ }^{\circ} \mathrm{C}\right. \\
\text { at } 760 \\
\mathrm{mmHg})\end{array}$} & \multirow{2}{*}{$\begin{array}{l}\mathrm{WS}^{4} \\
\left(\mathrm{~g} / \mathrm{L}, 25^{\circ} \mathrm{C}\right)\end{array}$} \\
\hline & & & $\mathrm{DE}$ & $\mathrm{MC}$ & MF & $\mathrm{PN}$ & & & \\
\hline & & & & & Alcohols & & & & \\
\hline 2-Pentanol & 1,123 & $1,2,3$ & 0 & 0 & 0 & $0.0066(0.0100)$ & 1.41 & 139 & 23.3 \\
\hline 1-Butanol & 1,147 & $1,2,3$ & $0.44(0.40)$ & $0.033(0.040)$ & 0 & 0 & 0.88 & 118 & 66.3 \\
\hline 2-Heptanol & 1,286 & 1,3 & 0 & $0.022(0.012)$ & 0 & 0 & 2.29 & 159 & 4.39 \\
\hline 1-Octanol & 1,551 & $1,2,3$ & 0 & 0 & $0.29(0.04)$ & $0.062(0.023)$ & 3.00 & 195 & 0.95 \\
\hline 2-Hexanone & 1,083 & 1,2 & 0 & 0 & $0.010(0.116)$ & 0 & 1.44 & 128 & 7.59 \\
\hline 1-Hydroxy-2-propanone & 1,298 & 1,2 & $0.085(0.028)$ & $0.48(0.52)$ & $0.12(0.01)$ & 0 & -0.78 & 146 & 553 \\
\hline Butyrolactone & 1,631 & $1,2,3$ & $0.020(0.003)$ & $0.032(0.019)$ & $0.039(0.022)$ & $0.020(0.004)$ & -0.76 & 204 & 281 \\
\hline Pantolactone & 2,029 & $1,2,3$ & $0.025(0.013)$ & $0.10(0.05)$ & $0.076(0.012)$ & $0.016(0.006)$ & -0.8 & 225 & 187 \\
\hline 2-Pyrrolidinone & 2,048 & 1,2 & 0 & $0.024(0.013)$ & 0 & 0 & -1.45 & 245 & 392 \\
\hline 2,5-Pyrrolidinedione & 2,458 & $\overrightarrow{1}$ & 0 & $0.017(0.001)$ & 0 & 0 & -1.18 & 288 & 176 \\
\hline Acetic acid & 1,436 & $1,2,3$ & $9.4(3.9)$ & $6.3(4.9)$ & $10.7(0.3)$ & $0.044(0.010)$ & -0.29 & 117 & 1,000 \\
\hline Formic acid & 1,485 & 1,2 & $0.97(0.42)$ & $0.0083(0.0028)$ & $7.2(0.7)$ & 0 & -0.54 & 101 & 1,000 \\
\hline Propionic acid & 1,523 & $1,2,3$ & $0.068(0.021)$ & $0.14(0.07)$ & $0.11(0.01)$ & $0.035(0.008)$ & 0.25 & 142 & 1,000 \\
\hline 2-Methyl-propanoic acid & 1,552 & $1,2,3$ & $0.020(0.007)$ & $0.041(0.021)$ & 0 & 0 & 0.59 & 155 & 1,000 \\
\hline 2,2-Dimethyl-propanoic acid & 1,563 & 1,2 & $0.0025(0.0014)$ & 0 & $0.041(0.017)$ & 0 & 0.94 & 166 & 185 \\
\hline Butanoic acid & 1,609 & $1,2,3$ & $0.14(0.04)$ & $0.35(0.19)$ & $0.25(0.02)$ & $0.21(0.03)$ & 0.78 & 164 & 578 \\
\hline 3-Methyl-butanoic acid & 1,652 & $1,2,3$ & $0.036(0.012)$ & $0.10(0.03)$ & $0.061(0.005)$ & $0.065(0.015)$ & 1.12 & 175 & 210 \\
\hline Pentanoic acid & 1,718 & $1,2,3$ & $0.0067(0.0024)$ & $0.017(0.008)$ & $0.011(0.003)$ & $0.0075(0.0017)$ & 1.31 & 185 & 171 \\
\hline Hexanoic acid & 1,828 & $1,2,3$ & $0.098(0.035)$ & $0.27(0.15)$ & $0.21(0.02)$ & $0.10(0.05)$ & 1.84 & 205 & 55.3 \\
\hline Heptanoic acid & 1,934 & $1,2,3$ & $0.15(0.08)$ & $0.55(0.31)$ & $0.017(0.004)$ & 0 & 2.37 & 223 & 19 \\
\hline 2-Ethyl-hexanoic acid & 1,934 & $1,2,3$ & $0.15(0.08)$ & $0.55(0.31)$ & 0 & 0 & 2.72 & 228 & 7.85 \\
\hline Octanoic acid & 2,042 & $1,2,3$ & $0.067(0.028)$ & $0.27(0.21)$ & $0.23(0.07)$ & $0.049(0.029)$ & 2.9 & 239 & 6.92 \\
\hline Nonanoic acid & 2,146 & $1,2,3$ & $0.015(0.005)$ & $0.047(0.028)$ & $0.045(0.009)$ & $0.013(0.003)$ & 3.43 & 255 & 2.68 \\
\hline (S)-2-Hydroxypropanoic acid & 2,159 & 1,2 & $3.0(1.2)$ & $0.64(0.41)$ & $2.6(1.9)$ & 0 & -0.7 & 228 & 1,000 \\
\hline Decanoic acid & 2,251 & $1,2,3$ & $0.068(0.044)$ & $0.64(0.33)$ & $0.24(0.11)$ & $0.041(0.031)$ & 3.97 & 270 & 1.1 \\
\hline 4-Oxo-pentanoic acid & 2,317 & 1 & 0 & $0.084(0.050)$ & 0 & 0 & -0.49 & 243 & 1,000 \\
\hline Benzoic acid & 2,417 & $1,2,3$ & 0 & $0.22(0.14)$ & $0.11(0.05)$ & 0 & 1.89 & 249 & 82.9 \\
\hline Dodecanoic acid & 2,467 & $1,2,3$ & $0.028(0.013)$ & $0.15(0.05)$ & $0.39(0.12)$ & 0 & 5.03 & 296 & 0.23 \\
\hline Phenylacetic acid & 2,539 & 1,2 & 0 & $0.048(0.026)$ & 0 & 0 & 1.5 & 266 & 65.7 \\
\hline Hexadecanoic acid & 2,570 & $1,2,3$ & 0 & $2.4(1.2)$ & $0.49(0.03)$ & $0.010(0.003)$ & 7.15 & 341 & 0.022 \\
\hline Tetradecanoic acid & 2,634 & $1,2,3$ & 0 & $0.033(0.010)$ & $1.0(0.5)$ & 0 & 6.09 & 320 & 0.062 \\
\hline Nonanal & 1,394 & $1,2,3$ & $0.0062(0.0044)$ & $0.0049(0.0014)$ & $0.022(0.003)$ & $0.016(0.002)$ & 3.56 & 191 & 0.084 \\
\hline 1-Piperidinecarboxaldehyde & 1,786 & 1,2 & $0.0017(0.0006)$ & 0 & $0.027(0.004)$ & 0 & 0.24 & 223 & 20.5 \\
\hline 1-Methyl-1H-pyrrole-2-carboxaldehyde & 2,093 & 1 & 0 & $0.0069(0.0031)$ & 0 & 0 & 0.26 & 196 & 28.4 \\
\hline 2-Butanamine & 1,333 & 1 & 0 & $0.0097(0.0083)$ & 0 & 0 & 0.75 & 62.9 & 1,000 \\
\hline 1-Pyrrole-2-carboxaldehyde & 2,023 & 1 & 0 & 0 & 0 & $0.0062(0.0041)$ & 0.64 & 219 & 12 \\
\hline 5-Methyl-thiazole & 2,132 & 1 & 0 & $0.31(0.012)$ & 0 & 0 & 0.9 & 142 & 7.86 \\
\hline
\end{tabular}


Table 2 (Continued). Alcohols, ketones, acids, aldehydes, amines, amides, esters, sulfur-containing compounds, aromatic compounds, and furanic compounds found in SWP using direct solvent extraction with diethyl ether, methyl formate, methylene chloride and pentane analyzed by GC-MS on a capillary polyethyleneglycol column (values in parentheses are standard deviations

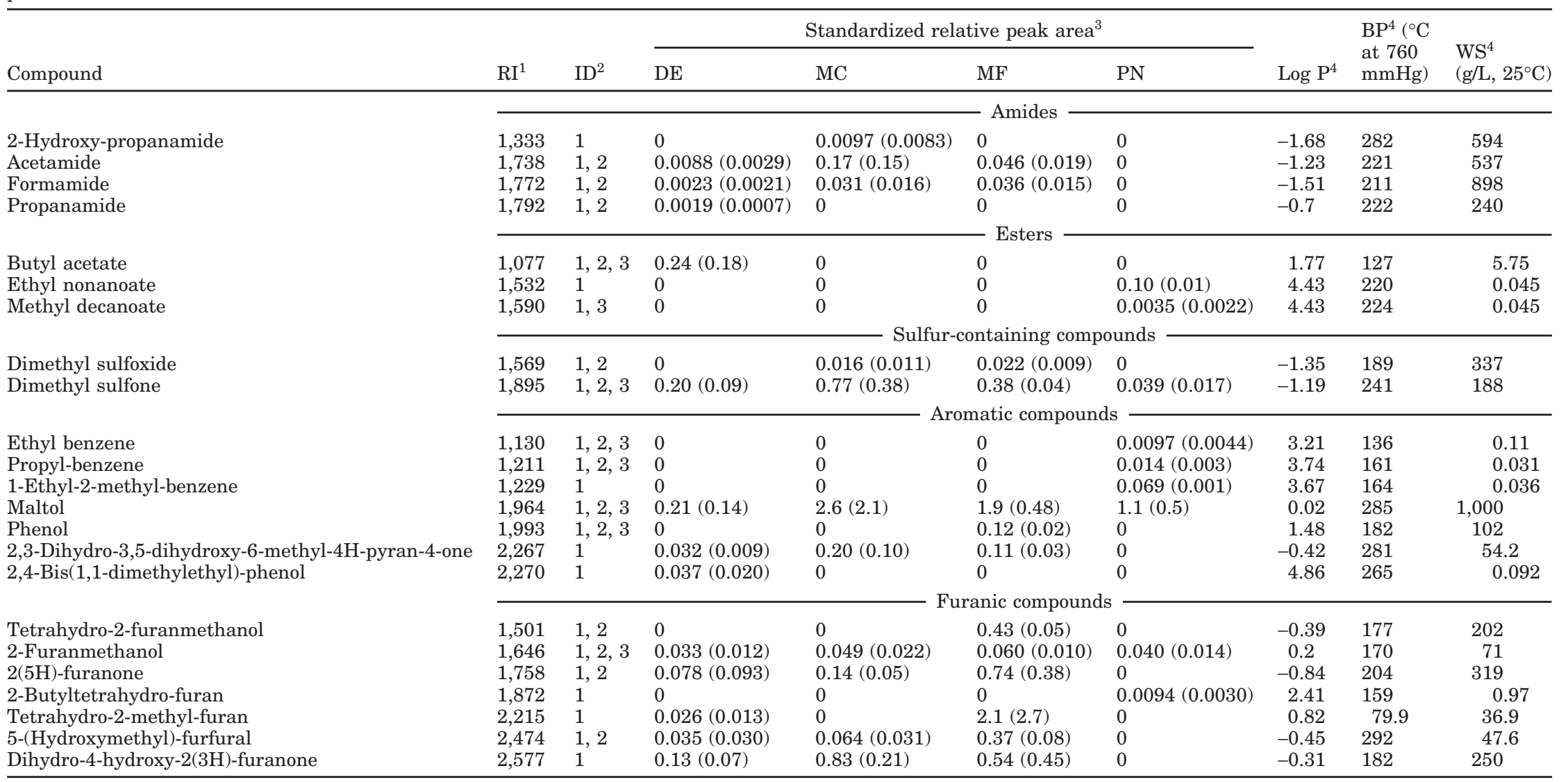

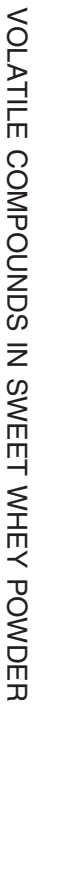

\footnotetext{
${ }^{1} \mathrm{RI}=$ Retention index.

${ }^{2}$ ID (identification of compounds): $1=$ mass spectrophotometer (match quality $>70 \%$ ); 2 = authentic standard; $3=$ reference Kovats index.
}

${ }^{3}$ Solvents: $\mathrm{DE}=$ diethyl ether; $\mathrm{MC}=$ methylene chloride; $\mathrm{MF}=$ methyl formate; $\mathrm{PN}=$ pentane.

${ }^{4}$ Values obtained from Advanced Chemistry Development, Inc., 2006. $\log \mathrm{P}=\log$ of octanol/water partition; BP = boiling point; WS = water solubility. 


\section{Diethyl ether}

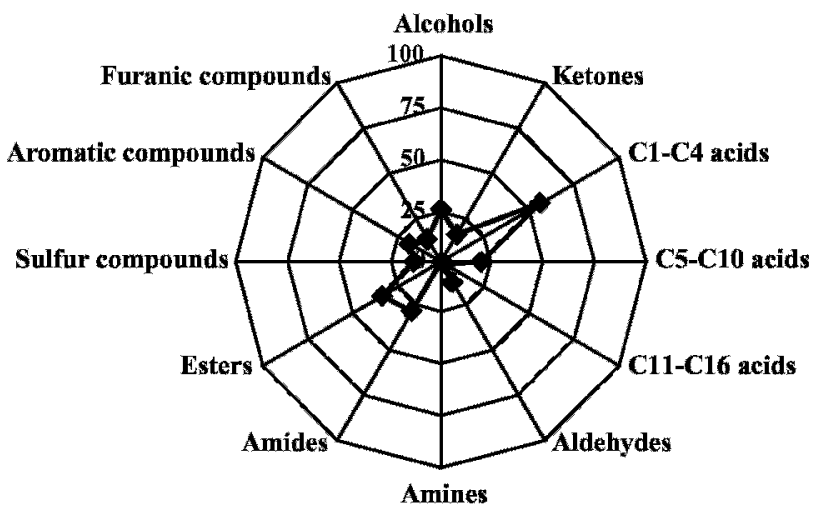

Methylene chloride

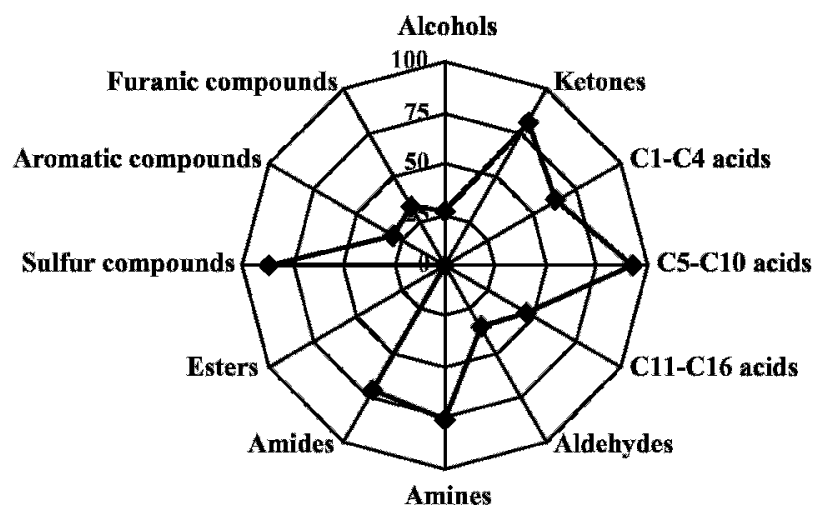

Methyl formate

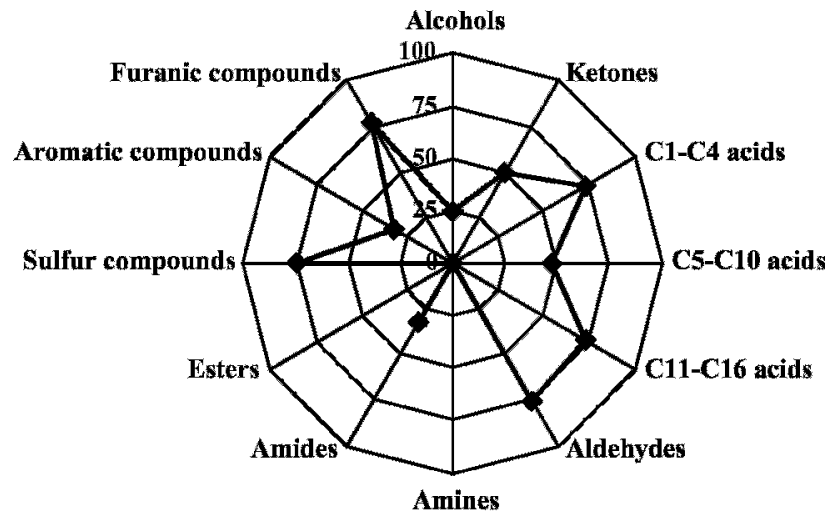

Pentane

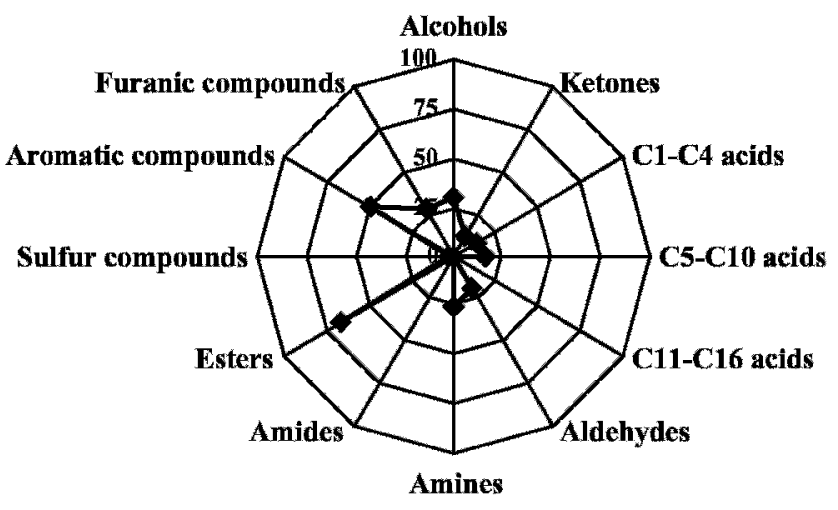

Figure 1. Average percentage relative peak area of compound classes using different solvents.

boxylic acids, aldehydes, sulfur-containing compounds, and furanic compounds; DE-no classes; PN-esters. Methylene chloride and MF had the greatest relative quantities for all classes of compounds combined compared with $\mathrm{PN}$ and DE. In addition to esters, PN was effective at extracting relatively large quantities of hydrocarbon aromatics (e.g., ethyl benzene, propyl benzene, and 1-ethyl-2-methyl benzene). Relative quantities for alcohols were distributed approximately equally between each solvent.

A notable observation was that the boiling points of the 60 flavor compounds were all very high and most well over $100^{\circ} \mathrm{C}$ (Table 2 ) with only 2 exceptions: 2 butanamine $\left(63^{\circ} \mathrm{C}\right)$ and tetrahydro-2-methyl-furan $\left(80^{\circ} \mathrm{C}\right)$. Flavor compounds having lower boiling points certainly exist in SWP (e.g., diacetyl, boiling point = $88^{\circ} \mathrm{C}$; Mahajan et al., 2004). However, because extraction is only one of the steps in the analysis of flavor compounds, solvent evaporation by nitrogen sparging being another, there may be flavor compounds having boiling points less than $100^{\circ} \mathrm{C}$ present in the matrix, but these were not detected due to possible losses during sample preparation or possible coelution with the solvent peak.

\section{DISCUSSION}

To understand the pattern of flavor compounds found using each of the 4 solvents, the physical properties of the solvents and flavor compounds were considered. Three molecular descriptors were selected for volatile flavor compounds: Log P, polarizability, and water solubility (Figure 2 and Table 2). Five molecular descriptors were selected for solvents: dipole moment, dielectric constant, Log P, polarizability, and water solubility (Figure 2 and Table 1). Diethyl ether and MF are weak 
Pentane chloride Methyl formate

Diethyl ether

Furanic compounds Aromatic compounds

Sulfur compounds

Esters

Amides

Amines

Aldehydes

C11-C16 acids

C5-C10 acids

C1-C4 acids

Ketones

Alcohols

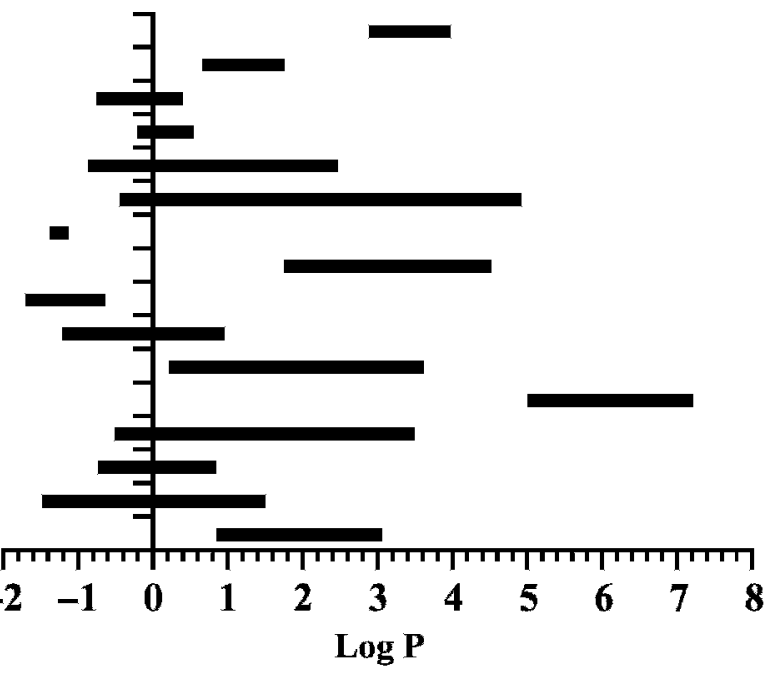

Pentane

Methylene chloride

Methyl formate

Diethyl ether

Furanic compounds

Aromatic compounds

Sulfur compounds

Esters

Amides

Amines

Aldehydes

C11-C16 acids

C5-C10 acids

C1-C4 acids

Ketones

Alcohols

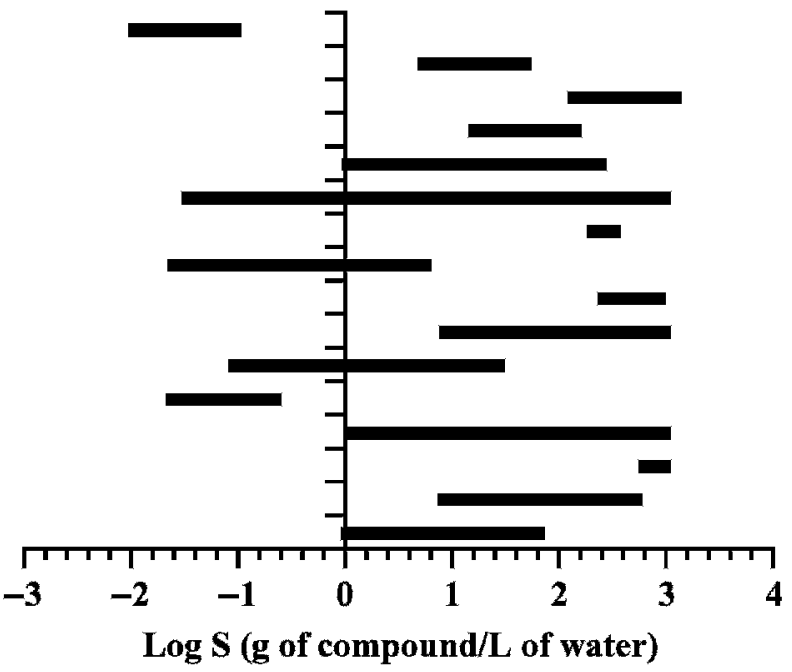

Methylene chloride

Methyl formate

Diethyl ether

Furanic compounds

Aromatic compounds

Sulfur compounds

Esters

Amides

Amines

Aldehydes

C11-C16 acids

C5-C10 acids

C1-C4 acids

Ketones

Alcohols

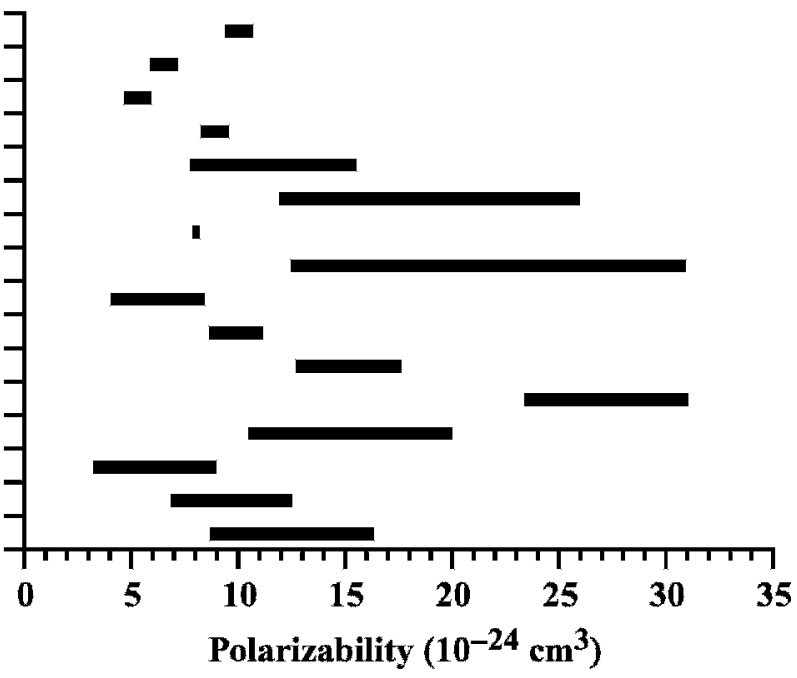

Figure 2. Range for properties of compound classes and solvents. $\log \mathrm{P}=\log$ of octanol/water partition; $\log \mathrm{S}=\log$ solubility (g/L). 
Lewis bases with MF being the weaker of the 2; MC and PN are neither Lewis bases nor acids. High polarity is indicated by a small $\log \mathrm{P}$ and polarizability value, large dipole moment and dielectric constant, and high water solubility. In general, MF is the most polar solvent followed by $\mathrm{MC}, \mathrm{DE}$, and then $\mathrm{PN}$.

The physical and chemical properties of the solvents affected detection of the different classes of compounds with polarity having the largest effect on compound number, distribution, and relative quantities (Table 2). For example, polar compounds such as ketones, shortchain carboxylic acids, amines, amides, sulfur-containing compounds, and furanic compounds were best detected using either MF or MC, the most polar solvents (Figure 1). Methyl formate was better than MC at selecting for $\mathrm{C} 1$ to $\mathrm{C} 4$ acids, $\mathrm{C} 11$ to $\mathrm{C} 16$ acids, aldehydes, and furanic compounds, whereas $\mathrm{MC}$ was better at selecting for ketones, C5 to C10 acids, amines, amides, and sulfur-containing compounds. Because MF is a weak Lewis base, it was expected and demonstrated to be effective at extracting acids. Furthermore, MC is the only solvent that exhibits a very slight acidity because of its ability to accept electron pairs, allowing for the possibility of improved solvation of basic compounds such as amides and amines. This may explain the better performance of $\mathrm{MC}$ compared with $\mathrm{MF}$ in detecting amides and amines.

This research shows that amines were best detected using MC. No amines were detected using DE and only 1 in 4 amines was detected using PN. Mahajan et al. (2004) found minor concentrations of pyrazine and other amine compounds in fresh SWP ( 14\% of the total compounds) by extraction with 2:1 PN:DE. Perhaps the PN component of their solvent blend was responsible for the recovery of the amines. In another study, Ferretti and Flanagan (1971) used MC as the solvent to extract SWP and found that up to $38 \%$ of the total compounds reported were amines, further confirming the performance of $\mathrm{MC}$ as effective for extracting amines.

Considering that $\mathrm{DE}$ is one of the most commonly used solvents in the extraction of volatile flavors from foods, it was interesting to note its relatively poor effectiveness in volatile compound extraction compared with other less utilized solvents. Because DE possesses the most basic character of the solvents evaluated, it would have been expected to detect the highest relative quantities of acids. However, this was not observed and was probably due to its slightly less polar character (lower dielectric constant and dipole moment) compared with $\mathrm{MC}$ and MF, suggesting that polarity plays a larger role in recovery of acidic volatile compounds than does acidity/basicity.
Pentane showed the highest selectivity for extracting aromatics and long-chain esters that are both relatively nonpolar compounds. Pentane is the least polar of the 4 solvents based on dielectric constant, dipole moment, $\log P$, and water solubility. It also has no solvent acidity or basicity. Therefore, it was expected and observed that PN would be most effective at extracting nonpolar and long carbon chain compounds. It was not surprising that PN did not achieve high relative quantities in the other flavor compound classes that are generally more polar and more basic than the aromatics and longchain esters.

The relative quantities of alcohols detected were approximately evenly distributed amongst all the solvents, which can be attributed to various physical and chemical properties. The alcohols detected are amphoteric and in general possess relatively high solvent basicity, moderate acidity, polarity, and polarizability, and low water solubility. Literature reports on general properties of alcohols can be applied to this research (Wypych, 2001): 1) polarizability increases with increasing n-carbon chain length, 2) basicity of n-alkanols increases with increasing chain length up to octanol, 3) acidity of n-alkanols decreases with increasing chain length up to nonanol, and 4) acidity of n-alkanols decreases dramatically with increasing alkylation at the atom that bears the hydroxyl group (e.g., from 1-butanol to 2-butanol). These properties exhibit competing forces between each solvent and may explain the even distribution of alcohols detected among the solvents.

The relative absence of flavor compounds having boiling points below $100^{\circ} \mathrm{C}$ can be attributed to a possible coelution of the compounds with the solvent peak and to the solvent evaporation step during sample preparation. During this latter step, the solvent is evaporated from approximately 75 to $0.5 \mathrm{~mL}-\mathrm{a} 150$-fold reduction. The loss of highly volatile flavor compounds during this step is governed by the relative volatility (RV) defined as the ratio of the vapor pressure of the solvent to that of the flavor compound. If $\mathrm{RV}>10$, then the loss of flavor compounds is small. Otherwise, the loss of volatile flavor compounds is significant and can be extreme. A Raleigh distillation calculation can be used to illustrate this point (King, 1980). Acetaldedyde, for instance (boiling point $=20^{\circ} \mathrm{C}$ ), has an $\mathrm{RV}$ value of 0.5 to 0.7 , and loss during this step is predicted to be greater than $99.9 \%$. For furan (boiling point $=31^{\circ} \mathrm{C}$ ), the RV is 0.7 to 1.0 , and loss is predicted to be $99.6 \%$. For formic acid (boiling point $=100.6^{\circ} \mathrm{C}$ ), RV is 10 to 14 , and loss is predicted to be $38 \%$. In agreement with this calculation, formic acid was detected in this study. However, for compounds having a lower boiling point and RV, losses during solvent evaporation probably caused the lack of detection of these flavor compounds. 
In future work, other solvents and combinations of solvents may provide additional information in this area of study. Because MC and MF performed best at extracting the highest number, widest distribution, and highest relative quantities of compounds, these solvents together might capture an even wider spectrum of compounds. Other solvents having a similar boiling point, but more acidic character, such as acetaldehyde or propionaldehyde, may also exhibit specific advantages.

\section{CONCLUSIONS}

The individual physical and chemical properties of the solvent and target flavor compound can only be used to a certain extent to predict extraction efficiency. This study demonstrates that no single molecular or physical property predominates as a predictor of the extraction performance against a particular class of compounds. However, it appears that solvent polarity has a great impact on flavor compound number, distribution, and relative quantities. Other factors such as food composition and matrix effects, $\mathrm{pH}$ adjustments, and solvent blending may be considered of interest in future work.

\section{REFERENCES}

Acree, T., and H. Arn. 2004. Subject: Kovats indices reference values. http://www.flavornet.org. Accessed Jan. 7, 2006.

Advanced Chemistry Development, Inc. 2006. Subject: Predicted values of boiling point, Log P, polarizability, and water solubility were obtained using the ACD/I-Lab Web service, (ACD/Log P/ Polarizability/Boiling Point/Water Solubility 8.02). http://ilab.acdlabs.com Accessed June 1, 2006.

AOAC. 2000. Official Methods of Analysis. Vol. I. 17th ed. Association of Official Analytical Chemists, Arlington, VA.

AOAC. 1995. Official Methods of Analysis. Vol. I. 16th ed. Association of Official Analytical Chemists, Arlington, VA.

ASI Instruments Inc. 2006. Subject: Dielectric Constant Reference Guide. http://www.asiinstr.com/technical/Dielectric\%20 Constants.htm\#Section\%20P Accessed July 10, 2006.

Banavara, D. S., D. Anupama, and S. A. Rankin. 2003. Studies on physiochemical and functional properties of commercial sweet whey powders. J. Dairy Sci. 86:3866-3875.
Buyong, M., J. H. Lii, and N. L. Allinger. 2000. Molecular polarizabilities and induced dipole moments in molecular mechanics. J. Comput. Chem. 21:813-825.

Catalan, J., and C. Diaz. 1997. A generalized solvent acidity scale: The solvatochromism of o-tert-butylstilbazolium betaine dye and its homomorph o,o'-di-tert-butylstilbazolium betaine dye. Eur. J. Org. Chem. 1997:1941-1949.

Catalan, J., C. Diaz, V. Lopez, P. Perez, J.-L. G. DePaz, and J.G. Rodriguez. 1996. A generalized solvent basicity scale: The solvatochromism of 5-nitroindoline and its homomorph 1-methyl5-nitroindoline. Eur. J. Org. Chem. 1996:1785-1794.

Chemical Land 21. 2000. Subject: Industrial Chemicals. http:// www.chemicalland21.com/industrialchem/icmenu01.htm\#SA Accessed Aug. 1, 2006.

El-Sayed, A. M. 2005. Subject: The Pherobase Database of Insect Pheromones and Semiochemicals. http://www.pherobase.com Accessed Dec. 11, 2006.

Engel, W., W. Bahr, and P. Schieberle. 1999. Solvent assisted flavour evaporation-a new and versatile technique for the careful and direct isolation of aroma compounds from complex food matrices. Eur. Food Res. Technol. 209:237-241.

Ferretti, A., and V. P. Flanagan. 1971. Volatile constituents of whey powder subjected to accelerated browning. J. Dairy Sci. 54:1764-1768.

Karagul-Yuceer, Y., K. R. Cadwallader, and M. A. Drake. 2002. Volatile flavor components of stored nonfat dry milk. J. Agric. Food Chem. 50:305-312.

Karagul-Yuceer, Y., M. A. Drake, and K. R. Cadwallader. 2001. Aroma-active components of nonfat dry milk. J. Agric. Food Chem. 49:2948-2953.

King, C. J. 1980. Uses and characteristics of separation processes. Pages 115-122 in Separation Processes. 2nd ed. McGraw Hill, New York, NY.

Kovats, E. 1958. Gas chromatographische Charakteriserung organischer Verbindungen. I. Retentions indices aliphatischer halogenide, alkohole, aldehyde und ketone. Helv. Chim. Acta 41:1915-1932.

Mahajan, S. S., L. Goddik, and M. C. Qian. 2004. Aroma compounds in sweet whey powder. J. Dairy Sci. 87:4057-4063.

Marth, E. H. 1985. Pathogens in Milk and Milk Products. Pages 4387 in Standard Methods for the Examination of Dairy Products. 15th ed. G. H. Richardson, ed. American Public Health Association, Washington, DC.

National Research Council. 1995. Prudent Practices in the Laboratory: Handling and Disposal of Chemicals. The National Academy Press, Washington, DC.

Sithole, R., R. McDaniel, and L. M. Goddik. 2005. Rate of Maillard browning in sweet whey powder. J. Dairy Sci. 88:1636-1645.

Wypych, G. 2001. Handbook of Solvents. ChemTec Publishing, Norwich, NY. 